\title{
Mobilidade e personalização como agentes centrais no acesso individual das mídias digitais
}

\author{
Eduardo Campos Pellanda \\ PUCRS \\ eduardo.pellanda@pucrs.br
}

\begin{abstract}
Resumo: $O$ trabalho em questão levanta problemas das relações entre o ambiente dos meios digitais, e suas possibilidades de personalização de conteúdo, e mídias impressas. No contexto de cibercultura e mobilidade da informação uma das questões centrais é a escolha de quando e o que se quer consumir, a questão é que nem todos os meios conseguem dialogar com este horizonte de maneira linear. Este é um primeiro ensaio sobre o inicio das pesquisas desenvolvidas no Laboratório de Documentos Digitais da FAMECOS/PUCRS que visa detectar e propor soluções para problemas de personalização de conteúdo.
\end{abstract}

Palavras-chave: Internet; mobilidade; mídia; personalização.

${ }^{1}$ Professor de Jornalismo online da Pontifícia Universidade Católica do Rio Grande do Sul (PUCRS) 
Nos primórdios da Internet comercial a então startup Amazon.com foi uma das expoentes da potencialidade de comunicação no espaço virtual. Tratava-se de uma empresa em um galpão que em poucos meses se tornou a maior livraria do planeta em número de vendas quanto de clientes. O efeito foi um dos alicerces para a expansão da rede e a criação relâmpago de diversas empresas que buscavam a mesma fórmula de negociação através de bits para a comercialização de produtos de átomos. Mas a passagem para a comunicação digital (Negroponte, 1995) significa mais do que a possibilidade de contato com milhares de consumidores em um espaço virtual. A Amazon.com acabou usando a possibilidade de armazenamento classificado de informações digitais (bancos de dados) em combinação com agentes inteligentes (VAZ, 1999) e cruzando interesses dos clientes com a classificação dos produtos para viabilizar sugestões de consumo personalizados. Estes dados podem ser atualizados em tempo real detonado por buscas no site ou compras efetivadas.

O caso da Amazon.com evidenciou que não somente em relação ao comércio mas também nas funções midiáticas da Internet a personalização de informações é um dos pontos de mutação em relação ao modelo um para todos das mídias massivas. A começar pelo acesso individualizado através de um "Computador Pessoal” (PC) ou até aparatos hiper-individuais de acesso (RHEINGOLD, 2003) como aparelhos celulares e palmtops a inteiração homem máquina é feita de maneira ponto-a-ponto até um ambiente de inteirações sociais que compõe o ciberespaço (LÉVY, 1999). A Internet então, não pode ser considerada uma mídia de massa como TV, Rádio ou Jornal embora hoje conte com perto de um bilhão de pessoas a lógica de acesso é outra. A rede é um meio em que pessoas acessam conteúdos e outras milhares de pessoas de maneira individual, trata-se de uma "Mídia de massa individual" como define Castells (2006).

Este trabalho é resultado das pesquisa desenvolvidas no Laboratório de Documentos Digitas de PUCRS em parceria com a empresa HP. O projeto visa testar experimentos que são mediados sob o viés da personalização. Estes testes são desenvolvidos paralelamente nas mídias impressa e online. O objetivo é apontar caminhos e metodologias para a personalização dos meios em oposição ao modelo tradicional de meios massivos, bem como entender quais os limites da personalização do ponto de vista da aceitação social. 
A questão que se impõe aqui é o contexto do leitor fragmentado e virtual (SANTAELLA, 2004) que esta envolto em uma atmosfera informacional transportada pelo ciberespaço que paradoxalmente não esta necessariamente perdido. A transformação para a "Mídia de massa individual" é resultado de uma busca pelo pessoal, pela diferença que leva a personalização. Essa diferença é uma contraposição de décadas de consumo de mídias massivas que não estão dialogando com possibilidades de manipulação do conteúdo digital:

"A mídia personalizada era uma das idéias da revolução digital no início da década de 90: a mídia digital iria nos "libertar" da "tirania" da mídia de massa, nos possibilitando consumir somente o que acharmos pessoalmente interessante" (JENKINS 2006, p244)

A personalização do consumo midiático viabilizado pela digitalização da informação (NEGROPONTE, 1995) permite o filtro por interesse de notícias e serviços na Internet e demais meios que estão em processo de migração do ambiente analógico como a TV e o Rádio. Mas, a cultura da personalização transpõe o ambiente midiático e se manifesta em adolescentes em diferentes perspectivas. Desde a personalização de roupas, cabelo e corpo através de tatuagens até adesivos, fundo de telas e artefatos amarrados a telefones celulares. Os iPods personalizam o que se escuta dentro de um universo de toda a biblioteca pessoal e foi elevado a um contexto de ícone cultural (JENKINS, 2006) que, com isso, ameaça o modelo de funcionamento das rádios FM.

Um dos efeitos mais claros em relação à mobilidade da Internet é o incremento da quantidade de interações, comunicações e fluxo de informações que este novo tipo de conexão com o ciberespaço pode proporcionar. Todavia, o severo aumento de diferentes tipos de comunicações não é sozinho o fato que leva a considerar o fenômeno complexo. A real complexidade aflora quando percebemos outros itens ligados a estas conexões, como ruídos e ambigüidades que este sistema gera. A mesma forma de comunicação que permite hoje a um soldado americano reconhecer seus caminhos em um deserto, serve também para uma pessoa achar o restaurante onde vai jantar com amigos que há muito não via. O mesmo indivíduo interagindo no Orkut pode potencializar laços de fraternidade ao mesmo tempo em que gera raiva de outros por apresentar conteúdos que difamam a imagem de membros de uma outra comunidade. O próprio Orkut nasceu da programação de um 
funcionário do Google que inicialmente não tinha fins lucrativos, mas como a empresa estava abrindo o capital na bolsa de valores o serviço ajudou a impulsionar as ações.

As previsões de George Orwell sobre a possibilidade cada vez maior que governos e empresas têm de vigiar os passos de cidadãos encontra vários suportes nas novas tecnologias móveis, pois é possível seguir os caminhos de um usuário de celular e usar esta informação de diversas maneiras. Contudo, simultaneamente os celulares com câmeras on-line estão se multiplicando e colocando teóricas vitimas no papel de Big Brother. A denúncia de tortura nas prisões iraquianas controladas pelo exército americano surgiu na Internet a partir de fotos tiradas com câmeras de U\$ 400.

O sistema de relações do ciberespaço, desta forma, tende a se complexificar não só pelo do aumento de interações mas também pelo número de efeitos que o acompanham. Torna-se reducionista a análise de qualquer fenômeno referente à mobilidade da Internet sem consideramos o objeto por vários ângulos e contradições.

Da possibilidade da escolha do consumo surgiu a colaboração em rede e a escrita coletiva (LÉVY, 1999) embaçou a fronteira de emissão e recepção liquefazendo as duas vias em um ambiente rizomático. A eclosão do "cidadão jornalista" (GILLMOR, 2004) é o movimento último da personalização do conteúdo, pois depois da filtragem para melhor adaptação da informação ao interesse do internauta ele agora edita o que achar mais pertinente em um contexto exemplificado pela Wikipedia.

A relação deste contexto com a tradição do modelo de mídia massiva esta tensionando a convergência dos modelos no ambiente digital. A Internet começou a sua fase comercial apropriando a linguagem dos jornais quando estes lançaram modelos transpostos para a rede. No transcorrer do tempo se traduziu para o meio online algumas características do jornal como a portabilidade e projeto gráfico.

O suporte portátil que o livro representava foi paulatinamente sendo considerado para "transportar" fatos do cotidiano. O "livro de notícias" só mais tarde foi evoluindo para se tornar jornal: "Nos séculos XVII e XVIII, um jornal não tem uma estrutura diferente daquela do livro" (Chartier, 1998, p.82). 
O jornal foi ainda mais além na questão da portabilidade por diversos motivos. Ele possuía textos mais curtos e segmentados em relação ao livro. Alem disso, a notícia precisava necessariamente ser lida durante o dia para continuar atualizada. O jornal, desta maneira, foi sendo utilizado nas ruas, nos transportes públicos, cafés e onde fazia pertinência. A mobilidade do meio jornal parece fazer parte de sua definição. Ele passa a ser levado, dobrado, rasgado e manipulado por vários leitores em seu ciclo de vida.

Por todas essas características, o jornal passa a ser o suporte para a narração de fatos diários e com isso possibilita a oficialização da função “jornalismo”. Este meio proporcionou o nascimento da proliferação de informações em massa. $O$ segundo passo foi deixar de ser simplesmente um apanhado de histórias do dia, mas sim um meio de reflexão e crítica da sociedade. Neste momento, o jornal começava a ocupar um lugar estratégico em propaganda de governos e grandes empresas.

A popularidade do jornal se deu quando a distribuição física foi ficando mais complexa. Por ser um produto baseado em átomos, e não ondas eletromagnéticas ou bits, o jornal precisa estar presente em lugares estratégicos. Quando foi percebido que a distribuição em esquinas, cafés, metrôs e outros pontos da cidade era a chave para a leitura de uma grande quantidade de pessoas, o meio passou a ser realmente consumido em massa. A estratégia de distribuição parece estar ligada ao jornal desde a sua origem. Nos tempos atuais, este é o único meio que precisa de uma distribuição física e, por isso, as empresas investem uma boa parte de recursos em planejamento logístico. Plantas remotas em cidades do interior parecem ter sido a solução para que jornais de grande circulação possam ter sua entrega descentralizada.

Se analisarmos o cenário atual, vemos que toda a etapa de edição e distribuição está digital (Negroponte, 1995). A captura do texto e da imagem pode ser feita diretamente por palmtops ou smartphones. A edição deste material se dá em um ambiente de redação em rede, onde a reportagem passa pelos editores, diagramadores e revisores. Depois desta etapa o conteúdo pronto é transmitido via rede para as diversas plantas de impressão em diferentes regiões de cobertura do jornal. Somente neste momento ocorre a transformação dos bits para átomos e a informação passa a circular em uma rede de distribuição analógica através de carros, caminhões, aviões e entregadores a pé ou de bicicleta. 
No momento da posse do jornal pelo leitor é que este poderá usufruir das qualidades de portabilidade e manuseabilidade deste meio. A informação pode ser compartilhada por pessoas próximas, mas, por sua característica analógica, o mesmo não pode ocorrer em relação a outras pessoas distantes fisicamente, a não ser que se utilize outra rede, a dos correios.

Uma análise preliminar deste processo pode levar a crer que este último passo analógico do jornal, o da impressão, está sendo pressionado a desaparecer, já que todas as outras etapas já estão digitais. Isso até pode realmente estar acontecendo neste momento, mas, até agora, os processos digitais serviram para impulsionar a mídia impressa a outro patamar. A rapidez na produção e as novas possibilidades de diagramação alteraram mais uma vez este meio.

A pressão da distribuição digital em rede é claramente forte frente a questões como o custo do papel, da distribuição e ainda da nãoatualização da informação ao longo do período de 24 horas, situação que piora com as edições de final de semana. Uma das maiores expectativas quando se analisa as possibilidades para a digitalização do jornal é em relação ao papel eletrônico ou ePaper desenvolvido por empresas como a Xerox, Kodak e Philips. Mas um dos problemas desta tecnologia é justamente o fato de obrigar as pessoas a levarem consigo, durante o dia, mais um aparato eletrônico.

A comunicação mediada por computadores tomou outra dimensão quando a Internet se tornou global e mais tarde comercial, o que levou à sua adoção massificada. A rede passou a ser uma killer app para o PC, que então se transformou em uma porta de entrada para o ciberespaço. Neste contexto, não se faz mais tão importante o processamento local de informações, que foi a base da computação pessoal e o principal argumento de consumo, mas a rapidez de conexão com a Internet, que significa também a quantidade de informações que podem ser trafegadas em um mesmo espaço de tempo. Todo o conceito do aparelho de computação pessoal é alterado de um dispositivo de processamento de aplicações de trabalho, como planilhas, e entretenimento, como jogos, para uma central de comunicação com IM, e-mails, pesquisas na WEB e mais recentemente telefonia. Mesmo estas aplicações de escritório e entretenimento passam a estar conectadas na rede como forma de trabalho colaborativo. 
O PC conectado à rede ganha, portanto, o status de aparato de comunicação e integra o processamento local ao compartilhamento de informações em nível global. O aumento paulatino dos chips de processamento, somado a uma diminuição do consumo de energia e desenvolvimento das redes telemáticas, proporcionaram a construção de computadores portáteis de mão e celulares com o mesmo poder de processamento de máquinas de alguns anos atrás.

Com isso, os fios se desamarram e o "cordão umbilical" que prende a computação em ambientes entre quatro paredes se solta. A energia proporcionada pelas novas baterias leva o internauta a ter a autonomia de uma jornada inteira de nomadismo até a volta à base. O novo dispositivo móvel, portátil e conectado passa a acompanhar o indivíduo, como suas roupas, carteiras e pastas, mas com outro nível de integração e interação homem x máquina.

Levando-se em conta que o aparato de computação para dentro de casa foi denominado computador pessoal, o dispositivo de computação móvel poderia ser chamado de computador hiper-pessoal. Se em um PC o uso é compartilhado com outros membros da família ou de um escritório, o dispositivo móvel é de uso estritamente individual. Este é o sentido do termo PDA (Personal Digital Assistent), cunhado no período de lançamento do Newton da Apple, que foi o primeiro computador de mão com o intuito de processar informações pessoais.

O celular como dispositivo de computação portátil interage com os indivíduos e expande as habilidades naturais para outras possibilidades. A "distância" entre os indivíduos e as máquinas diminui a cada possibilidade de portabilidade, usabilidade e ergonometria. A linha de evolução se dá desde "móveis pesados passando para aparatos de mesa (desktops) até computadores de mão e de vestir" (MITCHELL, 2003, p.64).

O ciberespaço parece envolver o mundo físico em um ambiente paralelo sempre disponível de maneira ubíqua. Este acesso constante através de dispositivos móveis torna o acesso mais intenso, direto e, conseqüentemente, mais transparente e invisível para os interagentes da rede. A telepresença, potencializada pelo acesso móvel, ao mesmo tempo em que não exige alguns deslocamentos no espaço das cidades, em outros potencializa a movimentação. Encontros sociais, flashmobs e 
manifestações políticas demonstram como estas rápidas formações de grupos podem ser potencializadas pela comunicação no espaço virtual. A combinação dos dispositivos móveis com o Google SMS, Google Earth e o Google tradicional transpõe as possibilidades de movimentação e conectividade entre o ambiente virtual e real. Este grau de conexão, novamente, potencializa todas as esferas da coletividade, desde a economia, mídia e entretenimento, até delitos e terrorismo. A sociedade está conectada de forma extensiva e tende a estreitar estes laços de ligações com os desenvolvimentos de rede, serviços e, paralelamente, a adoção pelos interagentes.

O tempo das interações na rede se altera igualmente com o quadro de conexões always on, onde a conexão acontece de maneira contínua e persistente. Alcançar qualquer pessoa em qualquer lugar gera uma inversão de espaços públicos e privados, forçando necessariamente as pessoas a alterarem hábitos e rotinas.

Até o presente momento a questão da interação entre pessoas no ambiente virtual era bem clara, se resumia a estar à frente de um computador e, quando a conexão se findava, ia-se para fora do ambiente da casa ou do escritório, para a vida "real" em festas, cinema, escolas, etc. Ao sair do lugar envolto por quatro paredes, hoje, se está ainda conectado em um "ambiente de mídias always on" que transcende as barreiras físicas e embaralha as fronteiras do real com o virtual. Se antes a discussão era pautada sobre os impactos da "vida on-line" na "vida real" hoje as duas são a mesma coisa. Evidente que não havia antes uma separação tão precisa entre o real que sempre potencializou o virtual e vice-versa (LÉVY, 1999), mas a percepção disto parecia ser mais clara. O "cordão-umbilical" da Internet fixa com as paredes se rompe e nasce uma rede nas ruas, nas praças e até em outros lugares entre paredes.

Em um ambiente onde sempre se tem uma possibilidade de conexão com aparelhos do cotidiano, como carros, telefones, câmaras, TVs e muitos outros, a própria questão do entendimento de mídia fica mais dispersa. Se o celular, o PC, o laptop, o relógio, o carro, o PDA se tornam receptores/transmissores de TV Digital, então a TV não será mais conhecida como a TV que hoje estabelecemos como uma caixa preta na sala. A linguagem de informação audiovisual composta pelo vídeo é o centro da questão, é o que vai determinar TV como mídia. Com efeito, a linearidade de acesso passa a dar caminho para em sujeito envolto em informações e linguagens neste ambiente de mídia always on . 
O Google já possui uma interface para celulares e PDAs e também para telefones móveis que só tenham SMS . A potencialidade de se possuir um Google portátil pode ser um agente modificador significativo da cibercultura. Portar uma janela para toda a atmosfera informacional que este sistema permite possibilita a descentralização completa do conhecimento. Se a Web tradicional tinha a capacidade de colocar a informação na mão do cidadão comum, a Internet móvel dispõe deste conhecimento para todos os indivíduos e "a qualquer momento". Desde a busca por um hospital mais próximo do lugar onde se está até dados sobre a construção de uma bomba usando materiais que podem ser comprados em supermercados, que também podem ser procurados, estão contidos nesta noosfera móvel.

Torna-se fundamental dizer que os dados podem estar contidos nos aparelhos, como aparelhos de MP3 como iPod, mas não está aí o verdadeiro poder proporcionado por esta tecnologia. $\mathrm{O}$ fato de a conexão à rede ser uma janela para $\mathrm{O}$ ciberespaço é o grande ponto de transformação. Cada indivíduo podendo conter toda a informação e o ambiente sendo alimentado pelo indivíduo é o modelo complexo do holograma proposto por Morin (1990). Esta relação já era observada em analogia à Internet tradicional, mas em um ambiente always on e ubíquo este fenômeno pode alcançar proporções ainda maiores.

A imaginação é um elemento que se soma a este contexto. A capacidade de simular e com isso chegar a novos pontos de pensamentos é uma das características da computação em rede. O "Memex", de Vannevar Bush (2002), é uma máquina de ligações de todas as informações de um indivíduo como livros e músicas que podem ser cruzadas em links e com isso ajuda a associação de pensamentos: "Considere um aparelho futuro para uso individual que é um tipo de biblioteca mecanizada individual, [...]. O Memex é um aparelho que individualiza e armazena todos os seus livros, discos e comunicações...” (BUSH, 2002, p.36).

Bush foi um pioneiro da questão da organização hipertextual como modelo de expansão da eficiência de relações, visto que o cérebro processa a informação por associações. A imaginação assim é potencializada por elementos derivados de links e simulações. A questão individual frisada por Bush é em relação ao indivíduo com os seus dados; mas, quando estes são dispostos em rede, a possibilidade de conexões aumenta em proporção exponencial. A máquina individual de Bush pode ser hoje o 
ciberespaço conectado pelo PC, com possibilidades ainda maiores do uso constante do indivíduo no contexto da mobilidade.

Como lembra Morin (2004, p.12), “...na atualidade, temos excesso de informação e insuficiência de organização, logo carência de conhecimento”. A questão da separação entre informação e conhecimento fica clara, assim como a premissa de que para haver conhecimento é preciso organização da informação.

$\mathrm{Na}$ era do ambiente de mídias always on proporcionado pelas tecnologias móveis não há dúvida que dados trafegam entre indivíduos de maneira mais rápida e intensa. A questão é: até que ponto isso pode ser transformado em conhecimento? Se pensarmos na questão da desordem das partículas da água quando a esquentamos, quanto mais se esquenta mais há chance das partículas começam a se colidir para passar para outro estágio. Este exemplo não se aplica integralmente com o processo de conhecimento, mas pode ser um ponto de partida. Criar mais conexões para que a informação possa ser trocada não garante por si só nem a ocorrência de comunicação e tampouco de geração de conhecimento. Mas, o aumento de conexões, em um primeiro momento e depois a busca pela sua organização, que precisa ser criada pelo meio e não imposta por padrões, podem encaminhar uma nova possibilidade de avanço de conhecimento.

A questão econômica que se impõe sobre a imagem da "sociedade da informação" é implícita nos casos de divulgação do produto wireless vendido pelas operadoras de telefonia móvel, mostrando a idéia da conexão potencializando a vida cotidiana. Isso é ressaltado na maioria dos discursos publicitários, por ser a maneira mais óbvia, no sentido de direta, para o entendimento do grande público. Esta fala é muito forte, justamente por não deixar de ter parte da razão. Com efeito, a conexão em si não traz conhecimento nem melhoria de vida. Não se pode aqui, de maneira nenhuma, olhar somente a superfície do discurso do mercado, que precisa necessariamente buscar novos públicos consumidores. Mas, pensando complexamente, não se pode esquecer casos em que a indústria tentou abrir mercados que não foram aceitos pelo público.

A rápida expansão da rede de celulares e conexões Wi-Fi, que podem ser consideradas a base para um novo ambiente wireless, não pode ser abordada somente 
por um viés de um movimento econômico em busca de um grande espaço novo de consumo. A identificação dos usos desta tecnologia pelos consumidores talvez tenha sido o grande ponto de sucesso da expansão rápida do ambiente sem-fio. Sempre levando em conta a questão dos vários fatores complexos, não se pode descartar também itens como o status causado por aparelhos de última geração e status de pertencer a um grupo social, e mais profundamente: estar conectado todo o tempo com este grupo.

A conexão com trocas de informações é constante e não é necessariamente entendida pelo público consumidor como transformação em conhecimento. O que precisa ser observado na mudança de rumo da cibercultura é como esta informação irá se organizar, resgatando Morin (2004).

O celular, agora caminhando para smartphone, parece ser resposta para este problema, pois se trata de um aparato que já está sendo levado por uma parcela considerável da população. O relatório da Associação Mundial de Jornais cita a experiência no Japão, por ter este país uma grande penetração de serviços além da voz. Ao mencionar o caso do Asahi Shimbun, que é o segundo maior jornal do Japão e do mundo, através do gerente de projeto, Takashi Ishioka, o relatório menciona o uso do celular para diversificar a distribuição:

Com uma circulação diária de 12 milhões de exemplares, não se pensa que o Asahi está preocupado com um declínio de vendas. Mas isso é inevitável por causa da competição com as novas mídias, conta Mr. Ishioka. O Asahi Shimbun adotou a estratégia de prover notícias e outros serviços através de telefones móveis na esperança de aumentar leitores do jornal.

Outro relatório, da mesma organização, ressalta a importância estratégica do celular: "Talvez a maior oportunidade de todas está na explosão dos aparelhos de telefonia móvel. O uso de telefones móveis deve superar o da Internet baseada em PC".

Torna-se importante destacar que o processo de digitalização do jornal é basicamente uma mudança de suporte da linguagem texto. Esta possível transformação implica mudanças culturais profundas advindas de uma longa história de consumo do meio impresso. Por este motivo, torna-se ainda prematura uma discussão baseada em datas para tais mudanças. 
O que se faz relevante neste momento é perceber que há uma sobreposição de conteúdos entre o jornal tradicional e os meios baseados em Internet. E isto aponta uma mudança futura nos dois ambientes para estabelecer um nicho de atuação de cada meio. Neste momento, a exemplo do Japão, outros países, principalmente escandinavos, estão usando o celular não exatamente como substituição, mas como uma nova maneira de acompanhar conteúdos com a mesma característica de mobilidade do jornal.

Os meios impressos em um contexto de cibercultura, onde as relações e trocas de informações entre indivíduos são transmitidas em tempo real, e, com isso, proporcionam uma satisfação ao interagente de forma instantânea remam contra uma corrente histórica que urge por transformações. Sistemas de editoração eletrônica aproximam o tempo do fechamento de jornais e revistas até o limite físico do tempo mínimo para a impressão e distribuição. Porém, a capacidade de filtrar e manipular a informação digital (NEGROPONTE 1995) é barrada na última fronteira que é o sistema de impressão e o suporte papel. A personalização é um conceito antagônico com a produção massiva do meio impresso. Este fato, tem retardado ainda mais a convergência do impresso com o contexto de cibercultura.

O intuito do projeto em questão é a junção das possibilidades de personalização digitais com a impressão. O centro da questão é a utilização de um software desenvolvido pela empresa HP para a personalização de conteúdos impressos. Este conteúdo começa a se aproximar das gerações de material para a Internet incluindo o papel em um outro contexto de importância.

O grupo de pesquisadores envolvidos no projeto gera revistas e matérias publicitárias personalizados paralelamente para mídias impressas e online. Uma das questões mais evidentes viabilizadas por esta técnica é a alteração de linguagem que intrínseca ao meio. O meio impresso é sinônimo de documento em um contexto histórico e social das mídias. Quando se altera este contexto há um impacto inicial que deverá ser medido no decorrer do projeto.

Outro ponto relevante na discussão é a eficiência na coleta de dados para a personalização. Em meios puramente digitais e em ambiente de rede, como a Internet, a verificação e atualização constante de preferências do interagente é parte 
integrante do processo. O sistema da loja Amazon.com deixa esta questão mais clara. O entendimento sobre preferências e relações é constante e atualizada a cada consulta ou compra, experiência esta dificilmente reproduzida no contexto das mídias impressas.

Enfim, convergir o meio impressa no ambiente da "Mídia de massa individual" (CASTELLS 2006) e torná-la mais receptiva para uma geração acostumada com um ambiente de cibercultura convergente (JENKINS 2006) e informações ubíquas viabilizadas por relações de SmartMobs (RHEINGOLD 2003) é uma tarefa complexa porém necessária. Hiatos e gaps de gerações estão afastando jovens acostumados a receber informações personalizadas da mídia impressa em favor da escolha imediata do ambiente digital. Este é o problema crucial da renovação deste meio que anseia por novas gerações para dialogar com a transição técnica e cultural da digitalização.

\section{Referências bibliográficas}

CASTELLS, Manuel, A era da intercomunicação, Le Monde, 24 Junho, 2006

CHARTIER, Roger. Aventura do livro ao navegador. São Paulo: UNESP, 1998.

BUSH, Vannevar. As we may think. In: SPILLER, Neil. Cyber Reader. New York: Phaidon Press, 2002.

GILLMOR, Dam. We the Media - Grassroots by the people, for the people. Sebastopol: O’Reilly Media, 2004.

JENKINS, Henry, Convergence Culture - Where old and new media collide, New York, New York University Press, 2006

KELLY, Kevin. New rules for the new economy. New York: Penguin Books, 1999.

LEVINSON, Paul. Cellphone. New York: Palgrave, 2004.

LÉVY, Pierre. Cibercultura. São Paulo: Ed. 34, 1999.

. Tecnologias da inteligência. São Paulo: Ed. 34, 1994.

LEVY, Steven. Making the ultimate map \& A future with nowhere to hide?, Nesweek Magazine, New York, jun. 2004. 
McLUHAN, Marshall. Os meios de comunicação como extensões do homem. São Paulo: Cultrix, 1964.

MEYROWITZ, Joshua. Global nomads in the digital veldt. In: NYÍRI (ed.). Mobile democracy. Essays on Society, Self and Politics, Vienna: Passagen Verlag, p.91 $102,2003$.

MITCHELL, William J. ME++ - The Cyborg Self and the Networked City. Boston: MIT Press, 2003.

MORIN, Edgar.. Comunicação, cultura e tecnologias do imaginário. Porto Alegre: Sulina, 2004.

NEGROPONTE, Nicholas. Vida Digital. São Paulo, Companhia das Letras, 1995.

RHEINGOLD, Howard. Smart Mobs. Cambridge: Perseus Publishing, 2003.

SANTAELLA, Lúcia. Navegar no ciberespaço - O perfil cogitivo do leitor imersivo, São Paulo, Paulus, 2004

SHANNON, C; WEAVER, W. The mathematical theory of communication. Urbana: University of Illinois Press, 1962.

THOMPSON, John B. A mídia e a modernidade: uma teoria social da mídia. Petrópolis: Vozes, 1998.

VAZ, Paulo. Agentes na Rede, In: Lugar Comum - Estudos de Mídia,Cultura e Democracia, Rio de Janeiro: NEPCOM, nº 7 (janeiro-abril), 1999. 